\title{
Differential branch pulmonary artery growth after the Norwood procedure with right ventricle-pulmonary artery conduit versus modified Blalock-Taussig shunt in hypoplastic left heart syndrome
}

Jay D. Pruetz, MD, ${ }^{a}$ Sarah Badran, MD, ${ }^{a}$ Fred Dorey, PhD, ${ }^{b}$ Vaughn A. Starnes, MD,${ }^{c}$ and Alan B. Lewis, MD $^{\mathrm{a}}$

\begin{abstract}
Objectives: The Norwood procedure with right ventricle-pulmonary artery conduit is thought to improve postoperative hemodynamics in hypoplastic left heart syndrome, but its effects on pulmonary artery growth are unknown. This study evaluated pulmonary artery growth after the Norwood procedure in patients with a right ventricle-pulmonary artery conduit as compared with patients with a modified Blalock-Taussig shunt.
\end{abstract}

Methods: A total of 159 patients at our institution underwent the Norwood procedure between January 2000 and September 2005. Patients were divided into group A or B if they had a modified Blalock-Taussig shunt $(\mathrm{n}=103)$ or a right ventricle-pulmonary artery conduit $(n=56)$. Angiograms from the pre-Glenn catheterizations were used to measure pulmonary artery size and assess shunt stenosis $(n=64)$.

Results: Fifty-five (53.4\%) patients in group A versus 40 (71.4\%) in group B underwent Glenn surgery. Group B patients often required an additional shunt (modified Blalock-Taussig) before the Glenn procedure because of hypoxemia $(8 / 40$ vs $1 / 55 ; P=.004)$. Branch pulmonary artery growth was better in group B patients who did not require an additional shunt (Nakata index $212 \mathrm{vs} 169 \mathrm{~mm}^{2} / \mathrm{m}^{2} ; P=.004$ ) and more balanced than in group A (right pulmonary artery/left pulmonary artery ratio $=1.02 \mathrm{vs} 1.39 ; P=.001$ ) as a result of greater left pulmonary artery size ( $\left.29 \mathrm{vs} 19 \mathrm{~mm}^{2} ; P=.001\right)$. However, group B experienced more shunt stenosis $(8 / 32 \mathrm{vs} 2 / 32 ; P=$ .001 ), underwent the Glenn operation earlier (192 vs 246 days; $P=.03$ ), and had central pulmonary artery hypoplasia develop more often than group A patients $(25 / 32$ vs $14 / 32 ; P=.01)$.

Conclusion: The Norwood procedure with a right ventricle-pulmonary artery conduit promotes better distal left pulmonary artery growth resulting in more balanced branch pulmonary artery size, but central pulmonary artery hypoplasia occurs more often. Early right ventricle-pulmonary artery conduit stenosis also increases the need for additional shunting or early Glenn surgery.

Hypoplastic left heart syndrome (HLHS) is a relatively uncommon form of congenital heart disease (CHD), accounting for less than $2 \%$ of all CHD, yet it accounts for the highest mortality among infants with CHD $(\sim 15 /$ $100,000){ }^{1}$ The most successful palliation for this complex form of CHD has been the Norwood procedure (NP), first introduced in 1983 and still the primary operation for HLHS. $^{2}$ The NP has undergone several modifications over the years, but perhaps none as controversial as the right ventricle-pulmonary artery (RV-PA) conduit used in place of a modified Blalock-Taussig shunt (mBTS). ${ }^{3,4}$ Since its emergence there has been much debate over the benefits of the RV-PA conduit. The main advantage anticipated with

From the Heart Institute, Children's Hospital Los Angeles, Los Angeles, Calif. Division of Cardiology, ${ }^{\mathrm{a}}$ Department of Pediatrics, ${ }^{\mathrm{b}}$ and the Division of Cardiothoracic Surgery, ${ }^{c}$ Department of Cardiothoracic Surgery, Keck School of Medicine, University of Southern California, Los Angeles, Calif.

Supported by the Paige Bronchick Clinical Scholar Fellowship Award.

Read at the Thirty-fourth Annual Meeting of The Western Thoracic Surgical Association, Kona, Hawaii, June 25-28, 2008.

Received for publication June 5, 2008; revisions received Oct 17, 2008; accepted for publication March 9, 2009.

Address for reprints: Jay D. Pruetz, MD, Division of Cardiology MS\#34, 4650 Sunset Blvd, Los Angeles, CA 90027 (E-mail: jpruetz@chla.usc.edu).

J Thorac Cardiovasc Surg 2009;137:1342-8

$0022-5223 / \$ 36.00$

Copyright $\odot 2009$ by The American Association for Thoracic Surgery

doi:10.1016/j.jtcvs.2009.03.019 the RV-PA conduit is decreased diastolic runoff into the pulmonary vascular bed resulting in higher systemic diastolic pressure and improved coronary blood flow. ${ }^{5-8}$ The physiology with the RV-PA conduit is believed to provide more stable immediate postoperative hemodynamics and reduced intermediate stage mortality. ${ }^{9-12}$ Another benefit proposed with the RV-PA conduit is greater flow pulsatility in the pulmonary artery (PA) promoting better PA growth over time. ${ }^{13}$ As a result, these patients might require less additional surgery to augment or repair their PAs at the subsequent stages of single ventricle palliation. ${ }^{14,15}$ Some reported disadvantages of the RV-PA conduit include increased incidence of shunt stenosis. ${ }^{16-18}$ This study sought to evaluate the differences in PA growth and PA surgical interventions after the stage I NP with the RV-PA conduit versus the mBTS to help guide future surgical decision-making for infants with HLHS.

\section{METHODS}

A retrospective review of the surgical database at our institution identified 159 patients who underwent stage I NP between January 2000 and September 2005. Patients presenting after September 2005 were enrolled in the single ventricle trial sponsored by the Pediatric Heart Network and were not included in the current series. Before initiation of the study the Committee on Clinical Investigations (institutional research board) approved the research protocol. Enrolled patients had severe obstruction to left ventricular (LV) outflow, hypoplasia of the LV, and a single 


\section{Abbreviations and Acronyms \\ $\mathrm{CHD}=$ congenital heart disease \\ HLHS = hypoplastic left heart syndrome \\ $\mathrm{LV}=$ left ventricle (ventricular) \\ mBTS = modified Blalock-Taussig shunt \\ $\mathrm{NP}=$ Norwood procedure \\ $\mathrm{PA}=$ pulmonary artery \\ PTFE = polytetrafluoroethylene \\ $\mathrm{RV}=$ right ventricle (ventricular) \\ $\mathrm{RV}-\mathrm{PA}=$ right ventricle-pulmonary artery}

\section{Surgical Procedure}

The stage I NP for each patient was performed by the same surgeon (V.A.S.) and consisted of atrial septectomy followed by aortic arch reconstruction using the main PA, native ascending aorta, and pulmonary homograft patch with the patient under deep hypothermic circulatory arrest. The PA bifurcation was patched with a polytetrafluoroethylene (PTFE) patch (Gore-Tex patch; W. L Gore \& Associates, Inc, Flagstaff, Ariz) after removal of the main PA. The final step involved the placement of either an mBTS using a PTFE tube (Gore-Tex tube) from the innominate artery to the right PA or placement of a PTFE conduit from the RV infundibulum just below the pulmonary valve to the central PA at the bifurcation (RV-PA conduit). The RV-PA conduit was typically placed to the left of the neoaorta ( $>95 \%$ of patients) and anastomosed directly to the PTFE patch on the PA bifurcation, whereas the mBTS was anastomosed directly to the right PA. No valved RV-PA conduits were used.

\section{Angiographic Analysis}

Pre-Glenn cardiac catheterizations performed at our institution were reviewed ( $\mathrm{n}=32$ in each group) with subgroup analysis of group B patients with only an RV-PA conduit $(\mathrm{n}=26)$. A single cardiologist (J.D.P.) reviewed all angiograms and performed off-line measurements of the PAs that were agreed on with a second observer (A.B.L.). The diameters of the right and left PAs were measured just proximal to the origin of the first-order PA branches (Figure 2) and used to calculate a Nakata index (combined right PA and left PA cross-sectional area indexed to body surface area). ${ }^{19} \mathrm{~A}$ ratio of right PA to left PA cross-sectional area was used for comparison of differential PA growth. All PA measurements were corrected on the QuantCore system (Siemens Medical Solutions, Malvern, Pa) and calibrated to known catheter diameter. Shunt stenosis was defined as greater than $50 \%$ narrowing of the shunt diameter and was correlated with intraoperative findings at time of surgery. Shunt-related PA stenosis was defined as greater than $50 \%$ narrowing of the PA diameter at the shunt insertion site compared with the adjacent PA diameter. Central PA hypoplasia was defined as narrowing of the central PA to greater than $50 \%$ of the combined average of right PA and left PA cross-sectional area.

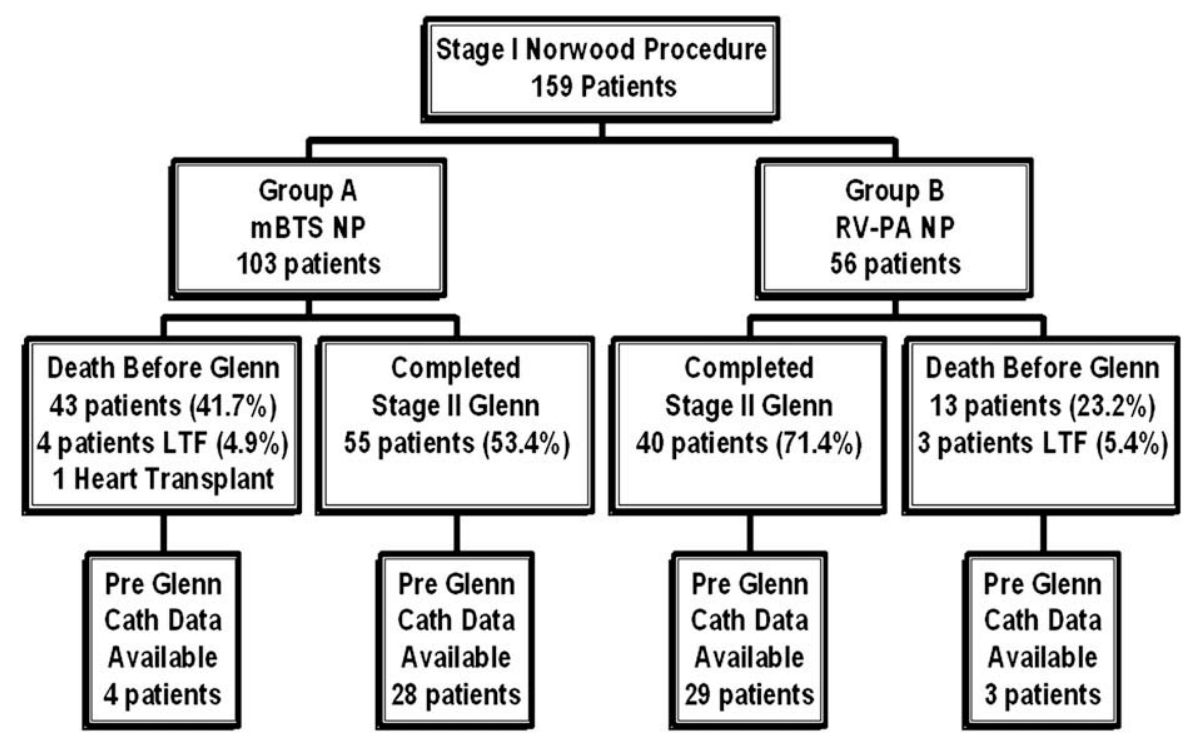

FIGURE 1. Flow chart of outcomes after the stage I NP with mBTS (group A) compared with RV-PA (group B) between January 2000 and September 2005. These data are expressed as total number of patients ( $\%$ of total study group). The lowest row of boxes denotes the primary study group ( $\mathrm{n}=32 \mathrm{in}$ each group). Cath, Catheterization; $L T F$, lost to follow-up; $m B T S$, modified Blalock-Taussig shunt; $N P$, Norwood procedure; $R V-P A$, right ventricle-pulmonary artery conduit. 

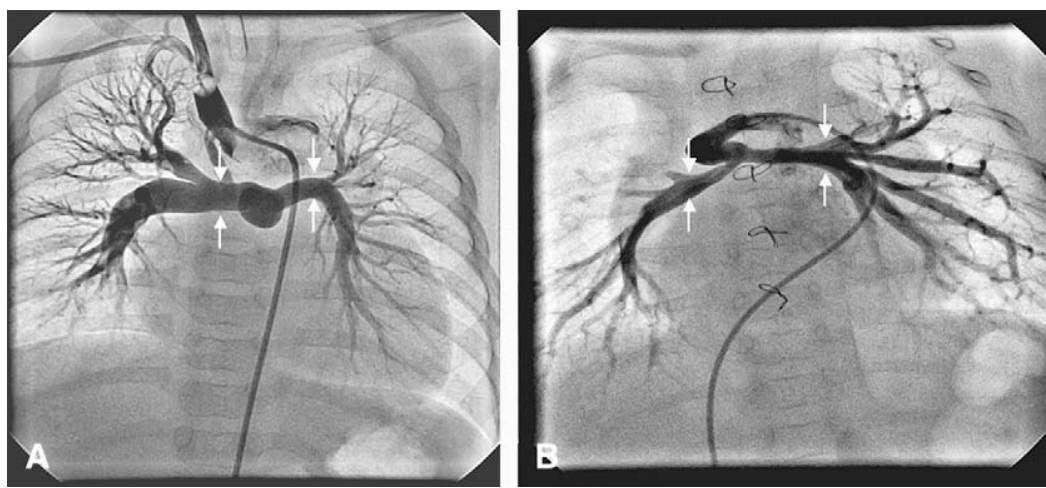

FIGURE 2. Angiograms performed at the pre-Glenn cardiac catheterization in a patient after stage I NP with mBTS (A) and RV-PA (B). Individual branch PA diameters were measured just before the takeoff of the upper lobe branch (white arrows). Note the central PA hypoplasia and shunt-related PA stenosis in panel B for the patient with RV-PA NP. $m B T S$, Modified Blalock-Taussig shunt; $N P$, Norwood procedure; $P A$, pulmonary artery; $R V-P A$, right ventriclepulmonary artery conduit.

\section{Statistical Methods}

Data were evaluated with standard statistical software (Stata SE version 10; Stata Corporation, College Station, Tex). Continuous variables are expressed as mean \pm standard deviation or median (range). Comparative univariate analyses were performed by the $t$ test, Mann-Whitney $U$ test, or Wilcoxon signed rank test, as appropriate. The $\chi^{2}$ test or 2-sided Fisher's exact test were used for ordinal and binomial data. Kaplan-Meier survival analysis was used to compare survival with that of the Glenn operation for both procedures with the competing risks of death as well as time to reintervention with an additional shunt if required before the Glenn operation.

\section{RESULTS}

No significant differences were seen between the two groups for demographic data or preoperative risk factors at the time of stage I NP (Table 1). Also, no difference was observed for the presence of aortic atresia versus aortic stenosis (group A $21 / 32$ vs group B 28/32; $P=.077$ ). Group A included 1 patient with Turner syndrome and 1 with asplenia syndrome. Group B included a patient with CHARGE association.* A notable surgical difference between the groups was the larger diameter of the RV-PA conduit compared with the mBTS $(5.3 \mathrm{vs} 3.6 \mathrm{~mm} ; P<.001)$. All patients were placed on an aspirin regimen postoperatively except for 1 patient in the RV-PA group owing to hypersensitivity reaction. Analysis of the entire study population revealed 8 patients in group B and 1 in group A who required an additional shunt before the Glenn operation $(8 / 40$ vs $1 / 55 ; P=$ .004). A Kaplan-Meier analysis to evaluate time to reintervention before the Glenn operation for the two groups showed a higher rate of additional shunt placement in the patients receiving an RV-PA conduit (Figure 3). This involved the placement of an additional mBTS in all cases. Pre-Glenn catheterization data for the primary study group showed no significant differences for age, weight, pulmonary flow, systemic flow, pulmonary/systemic flow ratio,

\footnotetext{
* CHARGE = coloboma, heart disease, atresia choanae, retarded growth and retarded development and/or central nervous system anomalies, genital hypoplasia, and ear anomalies and/or deafness.
}

or hemoglobin (Table 2). The RV-PA conduit was associated with better distal left PA growth and more balanced branch PA growth compared with the mBTS NP. The Nakata index tended to be higher overall for group B patients (202.9 vs $169.3 \mathrm{~mm}^{2} / \mathrm{m}^{2} ; P=.077$ ) and was significantly greater for the subset of group $B$ patients who did not require

TABLE 1. Demographic, preoperative risk factors, and stage I Norwood operative data

\begin{tabular}{|c|c|c|c|}
\hline & $\begin{array}{c}\text { Group A: mBTS } \\
\text { NP }(n=32)\end{array}$ & $\begin{array}{c}\text { Group B: RV-PA } \\
\text { NP }(\mathbf{n}=32)\end{array}$ & $P$ value \\
\hline \multicolumn{4}{|l|}{ Demographic data } \\
\hline Birth weight $(\mathrm{kg})$ & $\begin{array}{l}3.11 \pm 0.44 \\
(2.4-4)\end{array}$ & $\begin{array}{r}2.96 \pm 0.6 \\
(1.4-3.9)\end{array}$ & .26 \\
\hline Male/female ratio & $18: 14$ & $22: 10$ & .439 \\
\hline Age at Norwood (d) & $\begin{array}{l}12.3 \pm 16.9 \\
(1-79)\end{array}$ & $8.7 \pm 11.1(1-49)$ & .362 \\
\hline $\begin{array}{c}\text { Aortic atresia } \\
\text { present* }\end{array}$ & $21 / 32(65.6 \%)$ & $28 / 32(87.5 \%)$ & .077 \\
\hline \multicolumn{4}{|l|}{ Preoperative risk factors } \\
\hline Lowest $\mathrm{pH}$ & $\begin{array}{c}7.22 \pm 0.14 \\
(6.69-7.38)\end{array}$ & $\begin{array}{c}7.21 \pm 0.17 \\
(6.67-7.39)\end{array}$ & .827 \\
\hline $\begin{array}{l}\text { Highest lactate } \\
\text { level }(\mathrm{mg} / \mathrm{dL})\end{array}$ & $\begin{array}{r}57 \pm 66.3 \\
(14-223)\end{array}$ & $\begin{array}{r}60 \pm 57.5 \\
(19-227)\end{array}$ & .467 \\
\hline \multicolumn{4}{|l|}{ Stage I NP operative data } \\
\hline Bypass time (min) & $\begin{array}{r}43 \pm 18.9 \\
(26-128)\end{array}$ & $\begin{array}{r}36.8 \pm 8.7 \\
(20-64)\end{array}$ & .134 \\
\hline $\begin{array}{l}\text { Crossclamp time } \\
\quad(\min )\end{array}$ & $\begin{array}{c}42 \pm 18.6 \\
(30-69)\end{array}$ & $\begin{array}{c}39.9 \pm 18.3 \\
(22-53)\end{array}$ & .874 \\
\hline DHCA time (min) & $\begin{array}{c}38.3 \pm 8.7 \\
(5-52)\end{array}$ & $41.7 \pm 7.2(29-55)$ & .09 \\
\hline Shunt size $(\mathrm{mm})$ & $\begin{array}{c}3.64 \pm 0.26 \\
(3.0-4.5)\end{array}$ & $5.34 \pm 0.83(4-8)$ & $<.001$ \\
\hline $\begin{array}{l}\text { Additional shunt } \\
\text { before Glenn* }\end{array}$ & $1(3.1 \%)$ & $6(18.8 \%)$ & .02 \\
\hline
\end{tabular}




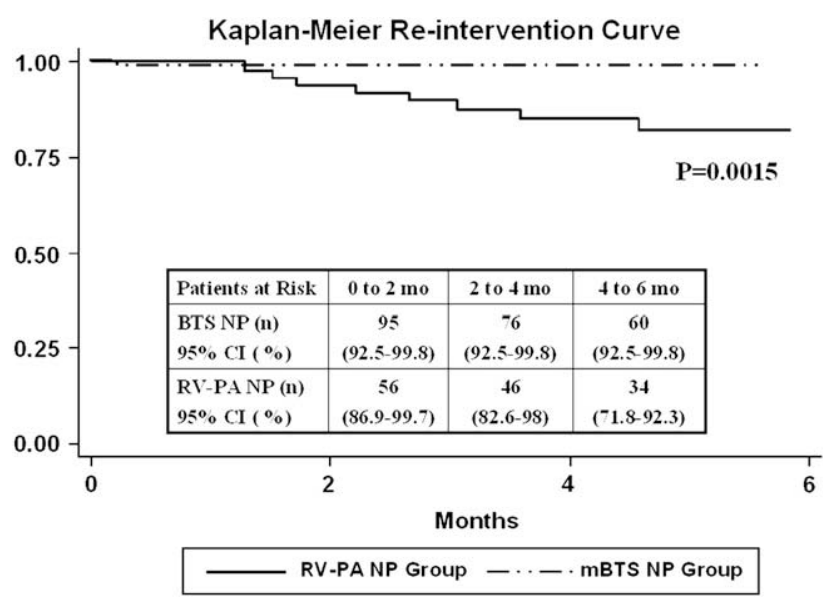

FIGURE 3. Kaplan-Meier reintervention curve for patients who underwent stage I NP with either mBTS versus RV-PA. Starting point is the day of stage I NP. No reinterventions occurred later than 6 months from the time of stage I NP. A stratified actuarial table displays the number of patients at risk in each group $(n)$ with $95 \%$ CI over 2-month intervals after stage I NP. CI, Confidence interval; $m B T S$, modified Blalock-Taussig shunt; mo, months; $N P$, Norwood procedure; $R V-P A$, right ventricle-pulmonary artery conduit.

an additional shunt (211.6 vs $\left.169.3 \mathrm{~mm}^{2} / \mathrm{m}^{2} ; P=.039\right)$. This was mainly due to the larger left PA cross-sectional area for group B patients ( 29 vs $\left.19 \mathrm{~mm}^{2} ; P=.001\right)$. The improved left PA size resulted in more balanced branch PA growth in the RV-PA conduit group with an observed right $\mathrm{PA} /$ left $\mathrm{PA}$ ratio of 1.02 versus 1.39 in the mBTS group $(P=.001)$. However, patients with an RV-PA conduit had a greater reduction in central PA size than their counterparts with an mBTS (40.6\% vs $60.2 \%$ mean reduction of central PA cross-sectional area). Thus, $78.1 \%$ of RV-PA patients met our criteria for central PA hypoplasia versus $43.8 \%$ of mBTS patients $(25 / 32$ vs $14 / 32 ; P=.01)$. Shunt stenosis developed in 14 of 32 group B patients compared with only 2 of 32 group A patients $(P=.001)$. Consequently, in our primary study group, 6 patients with an RV-PA conduit required additional shunts during the intermediate stage period versus only 1 additional shunt in mBTS patients $(6 / 32$ vs $1 / 32 ; P=.02)$. No patients underwent catheter-based interventions for alleviating RV-PA conduit or mBTS shunt stenosis. The incidence of shunt-related PA stenosis was not significantly different between the groups (group A 5/32 vs group $\mathrm{B} 8 / 32 ; P=.37$ ), and both had similar frequency of PA augmentation or repair at the time of the Glenn operation (group A 8/32 vs group B $7 / 32 ; P=.67$ ). Kaplan-Meier survival analysis was used to compare survival to Glenn surgery with the competing risk factor of death (Figure 4). We found a statistically significant improvement in survival to Glenn for the RV-PA group (40/56, 71.4\% survived) versus the mBTS group $(55 / 103,53.4 \%$ survived; $P=.042)$. RV-PA NP patients underwent Glenn surgery significantly earlier than mBTS NP patients (192 vs 246 days; $P=.028)$, weighed significantly less ( 5.53 vs $6.55 \mathrm{~kg} ; P=.005)$, and had lower arterial oxygen saturations at the time of Glenn surgery $(70 \%$ vs $75.5 \% ; P=.002)$.

\section{DISCUSSION}

\section{Main Findings}

The RV-PA modification to the NP has become widely accepted as an effective alternative to the standard NP

TABLE 2. Pre-Glenn cardiac catheterization data and stage II Glenn operative data

\begin{tabular}{|c|c|c|c|c|c|}
\hline & $\begin{array}{c}\text { Group A: mBTS } \\
\quad \text { NP }(n=32) \\
\end{array}$ & $\begin{array}{c}\text { Group B: All RV-PA } \\
\text { NP }(n=32) \\
\end{array}$ & $P$ value & $\begin{array}{c}\text { Sub-group B: RV-PA } \\
\text { NP only }(n=26) \\
\end{array}$ & $P$ value \\
\hline \multicolumn{6}{|l|}{ Cardiac catheterization data } \\
\hline Age at catheterization (d) & $164.1 \pm 52.2$ & $159.3 \pm 42.1$ & .682 & $149.4 \pm 38.0$ & .235 \\
\hline Qp/Qs ratio & $1.47 \pm 0.92$ & $1.22 \pm 0.63$ & .205 & $1.26 \pm 0.64$ & .633 \\
\hline $\operatorname{RPA} \operatorname{CSA}\left(\mathrm{mm}^{2}\right)$ & $30.8 \pm 16.9$ & $28 \pm 11.9$ & .450 & $29 \pm 12.9$ & .851 \\
\hline LPA CSA $\left(\mathrm{mm}^{2}\right)$ & $19 \pm 9.9$ & $29 \pm 13.4$ & .001 & $29.5 \pm 13.4$ & .001 \\
\hline Nakata index $\left(\mathrm{mm}^{2} / \mathrm{m}^{2}\right)$ & $169.3 \pm 78.2$ & $202.9 \pm 70.6$ & .077 & $211.6 \pm 72.6$ & .039 \\
\hline RPA/LPA ratio & $1.39 \pm 0.55$ & $1.02 \pm 0.24$ & .001 & $1.02 \pm 0.22$ & .001 \\
\hline Shunt stenosis* & $2(6.25 \%)$ & $14(44 \%)$ & .001 & $8(31 \%)$ & .032 \\
\hline Shunt-related PA stenosis* & $5(15.6 \%)$ & $8(25 \%)$ & .374 & $7(21.9 \%)$ & .342 \\
\hline Central PA hypoplasia* & $14(43.8 \%)$ & $25(78.1 \%)$ & .01 & $21(80.8 \%)$ & .009 \\
\hline \multicolumn{6}{|l|}{ Glenn operative data } \\
\hline Age at Glenn $(\mathrm{d})$ & $246 \pm 117.5(121-681)$ & $192 \pm 56.1(94-334)$ & .028 & $182.7 \pm 56.9(94-334)$ & .007 \\
\hline Weight at Glenn $(\mathrm{kg})$ & $6.55 \pm 1.53(4.4-10.8)$ & $5.53 \pm 1.03(3.2-7.6)$ & .005 & $5.37 \pm 0.95(3.2-6.9)$ & .002 \\
\hline Arterial $\mathrm{O}_{2}$ saturation $(\%)$ & $75.5 \pm 8.6(55-87)$ & $70 \pm 7.7(55-85)$ & .002 & $71.5 \pm 6.5(58-85)$ & .03 \\
\hline Bypass time (min) & $42.1 \pm 26.2(15-83)$ & $47.1 \pm 29.6(13-93)$ & 60 & $48.2 \pm 29.8(13-90)$ & .80 \\
\hline PA augmentation or repair* & $8(25 \%)$ & $7(26.9 \%)$ & .667 & $7(26.9 \%)$ & .667 \\
\hline
\end{tabular}

Mean \pm standard deviation (range). *These data are expressed as total number of patients (\% of primary study group). Subgroup B represents patients with RV-PA Norwood who did not undergo an additional shunting procedure. Both group B and subgroup B are compared with group A for analysis. CSA, Cross-sectional area; $L P A$, left pulmonary artery; $m B T S$, modified Blalock-Taussig shunt; $P A$, pulmonary artery; $Q p / Q s$, pulmonary/systemic flow rate; $R P A$, right pulmonary artery; $R V-P A$, right ventricle-pulmonary artery conduit; $S D$, standard deviation. 


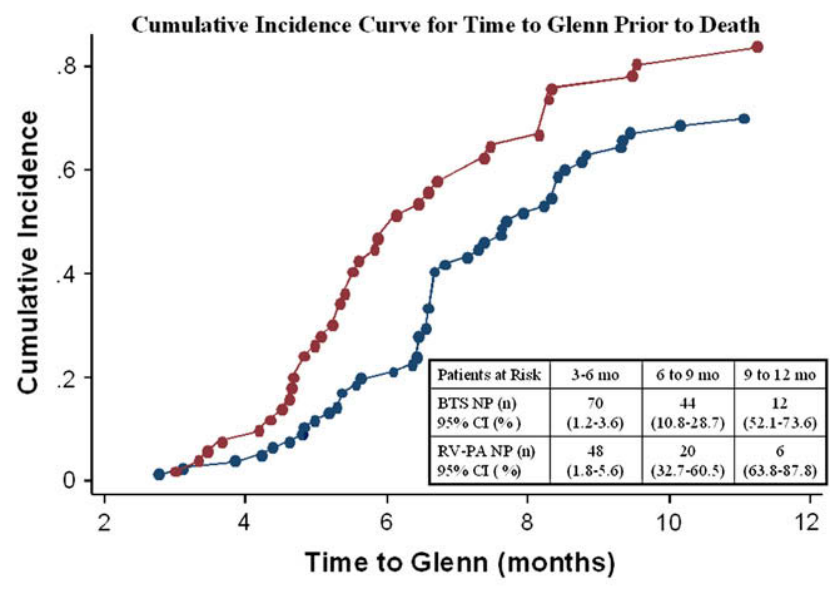

$\longrightarrow$ RV-PA NP Group $\ldots$ mBTS NP Group

FIGURE 4. Cumulative incidence curve for time to Glenn before death (survival to Glenn with competing risk of death) for patients who underwent stage I NP with either mBTS versus RV-PA. By 6 months, over $50 \%$ of RV-PA NP patients had completed the Glenn versus only $\sim 20 \%$ of mBTS NP patients. A stratified actuarial table displays the number of patients at risk in each group $(n)$ with $95 \%$ CI over 3-month intervals after stage I NP. CI, Confidence interval; $m B T S$, modified Blalock-Taussig shunt; $m o$, months; $N P$, Norwood procedure; $R V-P A$, right ventricle-pulmonary artery conduit.

with mBTS. This study sought to evaluate the differences in PA growth between the two surgical approaches as well as shunt-related surgical outcomes. Our research revealed that the NP with RV-PA conduit does result in significantly larger distal left PA size and more evenly balanced branch PA growth. However, there was a higher incidence of central PA hypoplasia. Earlier studies have shown improved PA growth in patients with an RV-PA conduit using a ratio of combined branch PA diameter to descending aorta diameter. ${ }^{7}$ Subsequent investigations confirmed a significantly greater left PA index for RV-PA patients using echo-derived measurements. ${ }^{8}$ More recently, Rumball and associates ${ }^{13}$ reported a $24 \%$ increase in the maximum indexed left PA diameter of patients with RV-PA conduit NP versus the mBTS NP using angiography. Similar to our study, they also found the left PA to be significantly smaller in the mBTS group. These results are consistent with Graham and associates, ${ }^{20}$ who showed larger PA size for RV-PA NP patients with a Nakata index of 270 versus $188 \mathrm{~mm}^{2} /$ $\mathrm{m}^{2}$ for mBTS patients $(P=.009)$. Our results were similar, but they also revealed the finding of significant central PA hypoplasia in the RV-PA group, which has not been widely described for this patient population. We originally hypothesized that the centralized PA insertion and more anatomically correct course of the RV-PA conduit would result in improved PA growth. This theory was in part due to a previous study at our institution, which showed that a more central insertion site for the mBTS to the main PA resulted in more balanced branch PA growth. ${ }^{21}$ Additionally, we surmised that the increased pulsatility of RV-PA blood flow would create improved expansion and recoil of the PAs, promoting better distal growth. However, we did not expect to find a higher incidence of central PA hypoplasia in the RV-PA group. It is possible that the anteroposterior course of the conduit may place tension on the branch PAs over time, causing them to narrow. Another possibility is compression from the neoaortic arch on the central PA, but this should occur equally in both groups. It is unclear what the long-term ramifications of such central PA hypoplasia will be for the RV-PA NP patients.

\section{Surgical Implications}

One can speculate that the smaller left PA size in the mBTS group or the higher incidence of central PA hypoplasia in the RV-PA group might lead to an increased need for PA augmentation during the Glenn operation for either group. In a recent report by Griselli and associates, ${ }^{18}$ the need to address central PA stenosis and PA hypoplasia was much higher in their RV-PA NP patients, $28 \%$ versus $98 \%$. However, in that study, PA augmentation was performed almost exclusively as part of the standard Glenn procedure, which is not the case at our institution. In our study population, additional PA surgical intervention was performed only as deemed necessary by the surgeon, which resulted in similar rates of PA augmentation for the 2 groups at the Glenn procedure. This was possibly due to the absence of a discrete or localized segmental stenosis that could adequately be addressed with surgical patch angioplasty. Both groups showed no major differences in outcomes on the basis of their PA growth by the Glenn surgery. However, differences in PA growth may affect long-term outcomes for these patients rather than short-term outcomes such as differences in oxygenation. This study was designed to investigate up to the Glenn stage, inasmuch as the mid to long-term outcomes related to PA growth are not yet known. Previous studies have suggested the RV-PA conduit provides more stable postoperative physiology resulting in lower postoperative mortality and improved early outcomes. ${ }^{9-12}$ Our survival analysis from stage I NP to Glenn for both groups with the competing risk of death showed a significant improvement in survival for the RV-PA NP patients (40/56 vs $55 / 103$ survived to Glenn; $P=.042$ ). This may be partially attributed to a learning curve for the NP as well as improvements in postoperative care from the earlier era of the mBTS to the more current era of the RV-PA conduit. It also may be skewed by the fact that the time between intermediate stages was significantly shorter in group B because the patients receiving RV-PA conduits often required earlier Glenn surgery than is customary at our institution or an additional shunt procedure (mBTS) before the Glenn operation because of worsening cyanosis. The RV-PA conduit had a tendency to obstruct, particularly at the proximal insertion site of the conduit into the RV infundibulum. This appeared 
to be caused by RV muscular ingrowth and compression of the conduit. As a result, the RV-PA NP patients went for Glenn surgery almost 2 months earlier and weighed on average $1 \mathrm{~kg}$ less than their counterparts with mBTS NP. The premature Glenn operation in RV-PA NP patients has been previously reported, but the RV-PA conduit patients in that study showed better weight gain. ${ }^{22}$ To deal with this problem of early conduit obstruction, our surgeon modified his technique for RV-PA conduit placement by coring out a small portion of the RV wall at the RV-PA insertion site (instead of a simple ventriculotomy) as well as more aggressive muscular RV infundibular resection just below the insertion site.

\section{Clinical Implications}

Our results suggest that patients after the RV-PA NP should be monitored more closely with frequent pulse oximetry checks to detect worsening cyanosis as a result of progressive conduit stenosis. A recent study showed that a home monitoring program for patients with HLHS that included daily weight and pulse oximetry checks could significantly reduced intermediate stage mortality after stage I NP. ${ }^{23}$ The RV-PA NP patients had better distal left PA growth and more balanced branch PA growth when compared with the mBTS NP patients, which may increase the success rate for the Fontan procedure and decrease the need for either surgical or catheter-based intervention to augment or stent narrowed PAs. ${ }^{24,25}$ However, this remains to be seen for these patients inasmuch as it is still unclear what impact their greater degree of central PA hypoplasia will have on the next stage of surgery. Although the adequacy of PA size is still somewhat controversial, it has been shown that a subset group of Fontan patients with small PAs have worse outcomes. ${ }^{26}$ Differences in the need for surgical and/or catheter-based intervention between these groups will likely become more evident after the Glenn operation. Our follow-up study will look specifically at the outcomes and clinical course for these patients through the early postoperative Fontan stage with a focus on surgical reintervention and catheter-based reintervention on the PAs. We hope the results of this follow-up study will further elucidate the impact of differential PA growth in these two surgical populations.

\section{Study Limitations}

The retrospective nature of this study limited our ability to control for patient selection bias and required the use of a historical control group for which we could not eliminate confounding variables. A significant number of patients had their cardiac catheterizations performed at outside institutions, which prevented inclusion in this study. It is possible that exclusion of these patients may have altered some of our results. The RV-PA group included 6 patients who received an additional shunt before the pre-Glenn catheterization that may have altered PA growth and skewed our measurements. However, subgroup analysis of the RV-PA patients without an additional shunt supported the overall findings. Angiographic analysis of the PAs was very challenging in this study population owing to high variability of PA structure and lack of uniformity of the angiographic data. The ongoing randomized, multicenter single ventricle reconstruction trial ideally will resolve many of these questions and avoid many of the limitations associated with retrospective studies.

\section{CONCLUSIONS}

The RV-PA NP promotes greater distal left PA growth, resulting in more balanced distal branch PA size in infants with HLHS by the time of the Glenn operation. However, it is also associated with a greater degree of central PA hypoplasia as well as a higher incidence of shunt stenosis that often results in earlier timing of Glenn surgery or additional shunt placement during the first intermediate stage owing to progressive cyanosis.

\section{References}

1. Boneva RS, Botto LD, Moore CA, Yang Q, Correa A, Erickson JD. Mortality associated with congenital heart defects in the United States: trends and racial disparities, 1979-1997. Circulation. 2001;103:2376-81.

2. Norwood WI, Lang P, Hansen DD. Physiologic repair of aortic atresia-hypoplastic left heart syndrome. N Engl J Med. 1983;308:23-6.

3. Sano S, Ishino K, Kawada M, Arai S, Kasahara S, Asai T, et al. Right ventriclepulmonary artery shunt in first-stage palliation of hypoplastic left heart syndrome. J Thorac Cardiovasc Surg. 2003;126:504-10.

4. Mahle WT, Cuadrado AR, Tam VK. Early experience with a modified Norwood procedure using RV-PA conduit. Ann Thorac Surg. 2003;76:1084-8.

5. Malec E, Januszewska K, Kolcz J, Mroczek T. Right ventricle-to-pulmonary artery shunt versus modified Blalock-Taussig shunt in the Norwood procedure for hypoplastic left heart syndrome-influence on early and late haemodynamic status. Eur J Cardiothorac Surg. 2003;23:728-34.

6. Mair R, Tulzer G, Sames E, Gitter R, Lechner E, Steiner J, et al. Right ventricular to pulmonary artery conduit instead of modified Blalock-Taussig shunt improves postoperative hemodynamics in newborns after the Norwood operation. J Thorac Cardiovasc Surg. 2003;126:1378-84.

7. Maher KO, Pizarro C, Gidding SS, Januszewska K, Malec E, Norwood WI, et al. Hemodynamic profile after the Norwood procedure with right ventricle to pulmonary artery conduit. Circulation. 2003;108:782-4.

8. Januszewska K, Kołcz J, Mroczek T, Procelewska M, Malec E. Right ventricleto-pulmonary artery shunt and modified Blalock-Taussig shunt in preparation to hemi-Fontan procedure in children with hypoplastic left heart syndrome. Eur $J$ Cardiothorac Surg. 2005;27:956-61.

9. Pizarro C, Mroczek T, Malec E, Norwood WI. Right ventricle to pulmonary artery conduit reduces interim mortality after stage 1 Norwood for hypoplastic left heart syndrome. Ann Thorac Surg. 2004;78:1959-64.

10. Pizarro C, Norwood WI. Right ventricle to pulmonary artery conduit has a favorable impact on postoperative physiology after Stage I Norwood: preliminary results. Eur J Cardiothorac Surg. 2003;23:991-5.

11. Bradley SM, Simsic JM, McQuinn TC, Habib DM, Shirali GS, Atz AM. Hemodynamic status after the Norwood procedure: a comparison of right ventricle-topulmonary artery connection versus modified Blalock-Taussig shunt. Ann Thorac Surg. 2004;78:933-41.

12. Ohye RG, Ludomirsky A, Devaney EJ, Bove EL. Comparison of right ventricle to pulmonary artery conduit and modified Blalock-Taussig shunt hemodynamics after the Norwood operation. Ann Thorac Surg. 2004;78:1090-3.

13. Rumball EM, McGuirk SP, Stumper O, Laker SJ, de Giovanni JV, Wright JG, et al. The RV-PA conduit stimulates better growth of the pulmonary arteries in hypoplastic left heart syndrome. Eur J Cardiothorac Surg. 2005;27:801-6.

14. Tchervenkov CI, Chedrawy EG, Korkola SJ. Fontan operation for patients with severe distal pulmonary artery stenosis, atresia or a single lung. Semin Thorac Cardiovasc Surg Pediatr Cardiol Surg Annu. 2002;5:68-75. 
15. Alboliras ET, Chin AJ, Barber G, Helton JG, Pigott JD, Norwood WI. Pulmonary artery configuration after palliative operations for hypoplastic left heart syndrome. J Thorac Cardiovasc Surg. 1989;97:878-85.

16. Eicken A, Genz T, Sebening W. Stenting of stenosed shunts in patients after a Norwood-Sano operation. Catheter Cardiovasc Interv. 2006;68:301-3.

17. Eicken A, Sebening W, Genz T, Schreiber C, Hess J. Stenting of a stenosed Sano shunt in a neonate with hypoplastic left heart syndrome. Pediatr Cardiol. 2005;26:877-8.

18. Griselli M, McGuirk SP, Ofoe V, Stumper O, Wright JG, de Giovanni JV, et al. Fate of pulmonary arteries following Norwood Procedure. Eur J Cardiothorac Surg. 2006;30:930-5.

19. Nakata S, Imai Y, Takanashi Y, Kurosawa H, Tezuka K, Nakazawa M, et al. A new method for the quantitative standardization of cross-sectional areas of the pulmonary arteries in congenital heart diseases with decreased pulmonary blood flow. J Thorac Cardiovasc Surg. 1984;88:610-9.

20. Graham EM, Atz AM, Bradley SM, Scheurer MA, Bandisode VM, Laudito A, et al. Does a ventriculotomy have deleterious effects following palliation in the Norwood procedure using a shunt placed from the right ventricle to the pulmonary arteries? Cardiol Young. 2007;17:145-50.
21. Batra AS, Starnes VA, Wells WJ. Does the site of insertion of a systemic-pulmonary shunt influence growth of the pulmonary arteries? Ann Thorac Surg. 2005; 79:636-40.

22. Lai L, Laussen PC, Cua CL, Wessel DL, Costello JM, del Nido PJ, et al. Outcomes after bidirectional Glenn operation: Blalock-Taussig shunt versus right ventricleto-pulmonary artery conduit. Ann Thorac Surg. 2007;83:1768-73.

23. Ghanayem NS, Hoffman GM, Mussatto KA, Cava JR, Frommelt PC, Rudd NA, et al. Home surveillance program prevents interstage mortality after the Norwood procedure. J Thorac Cardiovasc Surg. 2003;126:1367-77.

24. Senzaki H, Isoda T, Ishizawa A, Hishi T. Reconsideration of criteria for the Fontan operation. Influence of pulmonary artery size on postoperative hemodynamics of the Fontan operation. Circulation. 1994;89:1196-202.

25. Hosein RB, Clarke AJ, McGuirk SP, Griselli M, Stumper O, De Giovanni JV, et al. Factors influencing early and late outcome following the Fontan procedure in the current era. The 'Two Commandments'? Eur J Cardiothorac Surg. 2007; 31:344-53.

26. Bartram U, Grunenfelder J, Van Praagh R. Causes of death after the modified Norwood procedure: a study of 122 postmortem cases. Ann Thorac Surg. 1997;64:1795-802. 